\title{
A INFLUÊNCIA DA INSTITUIÇÃO FORMAL NO PROCESSO DE INTERNACIONALIZAÇÃO DAS MPMES EM UMA ECONOMIA EMERGENTE
}

Ane Izabelle Bezerra de Arruda ${ }^{1}$ e Viviane Santos Salazar

Universidade Federal de Pernambuco - UFPE, Recife, (Brasil)

\section{DETALHES DO ARTIGO}

\section{Histórico do Artigo:}

Recebido em: 16 de janeiro de 2020

Aceito: 27 de agosto de 2020

Disponível online: 01 de janeiro de

2021

\section{Sistema de revisão "Double blind review"}

\section{Editor Científico}

Ilan Avrichir

\section{Palavras-chaves:}

Instituição formal

Visão baseada na instituição

Programa de promoção à exportação

Internacionalização

\section{RESUMO}

Objetivo: O objetivo desse artigo consiste em analisar como um programa de promoção à exportação, enquanto instituição formal, influencia no processo de internacionalização das MPMEs de uma economia emergente, sob a perspectiva teórica da visão baseada em instituição.

Método: Foi realizado estudos de casos múltiplos, contemplando um corpus de 9 entrevistas realizadas de forma semiestruturada, com representantes da instituição formal em análise e MPMEs do setor têxtil e de confecção do Agreste Pernambucano.

Principais Resultados: Foi identificado uma influência significativa da instituição formal para a internacionalização das MPMEs do Setor T\&C, especialmente na desmistificação dos mitos da exportação, informações sobre os procedimentos para internacionalizar, promoção e apoio em feiras, ajustes em processos, produtos e gestão. Contudo há também influências negativas como a incipiente atenção a temática de comércio exterior, divulgação do programa com interesses políticos, poucos resultados práticos de exportação, burocracia do Estado e volatilidade cambial.

Relevância: O enfoque no papel das instituições do país de origem, especialmente, em economias emergentes, na internacionalização de empresas, é um tema emergente, portanto, esse artigo pode colaborar para a permanência da relevância local e global do tema

Contribuições Teóricas/ Metodológicas: Utiliza a perspectiva teórica da visão baseada em instituição para compreender as interações entre instituição e internacionalização, contemplando um ambiente institucional distinto, trazendo novas perspectivas para análise. 


\section{INTRODUÇÃO}

O dinamismo dos mercados proporcionado pela globalização, permitiu uma maior conexão entre os países do mundo e possibilitou a expansão dos negócios para mercados internacionais. O Brasil experimentou essa ruptura de fronteiras na década 90, e apesar da internacionalização tardia, se comparada ao mundo desenvolvido, às empresas brasileiras vêm investindo no mercado externo e obtendo resultados significativos com essa expansão (COSTA et al., 2017; MORAES; STREHLAU; TUROLLA, 2015).

Por estratégia de internacionalização das empresas entende-se como "o processo pelo qual a empresa deixa de operar nos limites do mercado nacional de origem e passa a explorar mercados estrangeiros, atuando de diferentes modos, desde mediante a simples exportação indireta até operações estrangeiras mais complexas" (BORINI et al., 2006). A decisão de entrar em um mercado internacional demanda das empresas um planejamento do processo e estabelecimento das melhores estratégias visando à obtenção de vantagem competitiva (DIAS, 2002), principalmente quando estas empresas estão localizadas em economias emergentes.

As economias emergentes estão aumentando a sua importância na economia global (NGO et al., 2016), pois além de receberem uma grande quantidade de investimentos direto externo (IDE) têm também investido diretamente em outros países. Portanto, é possível observar uma mudança no fluxo do processo de internacionalização que passa a englobar também as economias emergentes (XU; MEYER, 2013).

Contudo, fazia-se necessário a existência de teorias de internacionalização que abrangessem o ambiente institucional distinto das economias emergentes em termos políticos, econômicos e sociais. Pois grande parte das teorias existentes foram desenvolvidas em países desenvolvidos que possuem um ambiente político, social e econômico totalmente diferente das economias emergentes (WRIGHT; FILATOTCHEV; HOSKISSON, 2005). Uma das teorias que emergiu sobre esta temática foi a visão baseada em instituição que aliada a visão baseada em recursos (BARNEY, 1991) e a visão baseada na indústria (PORTER, 1980), compõe um tripé estratégico que busca explicar a estratégia e o desempenho das empresas nos mercados internacionais (PENG; WANG; JIANG, 2008). Essa perspectiva teórica reconhece as particularidades que influenciam o processo de internacionalização das empresas, especialmente, as de economias emergentes, como as mudanças constantes nas regras formais e informais do seu ambiente institucional (CUERVO-CAZURRA, 2012; NGO et al., 2016).

As transições institucionais constantes nas economias emergentes fazem com que muitas empresas se internacionalizem a fim de proteger-se das incertezas ambientais (MONTICELLI et al., 2017). Ademais, é possível perceber, também, nos últimos anos, uma atitude proativa do governo das economias emergentes no incentivo à exportação das empresas, inclusive de Micro, Pequeno e Médio porte.

Uma dessas iniciativas é a da Agência Brasileira de Promoção de Exportações e Investimentos (APEX) que é uma Instituição Formal que conduz programas como o Projeto Extensão Industrial Exportadora (PEIEX) com vistas a preparar as MPMEs de forma planejada e segura para o mercado externo e com isso, criar uma expertise exportadora na região. Diante do exposto, esse estudo busca responder a seguinte pergunta de pesquisa: Como um programa de promoção à exportação, enquanto instituição formal, influencia no processo de internacionalização das MPMEs em uma economia emergente?

Portanto, o objetivo do estudo consiste em analisar a influência de um programa de promoção à exportação, enquanto instituição formal, no processo de internacionalização das MPMES em uma economia emergente.

Para tanto, escolheu-se como suporte teórico a teoria neoinstitucional e a visão baseada em instituição com foco nas instituições formais. De modo a atender ao objetivo da pesquisa, adotou-se a metodologia qualitativa (GUBA; LINCOLN, 2005), e como estratégia de pesquisa, o estudo de casos múltiplos que contemplou um corpus de nove entrevistas semiestruturadas, com representantes tanto da instituição formal em análise, quanto das Micro, Pequenas e Médias Empresas( MPMEs) do setor têxtil e de confecção (T\&C) do Agreste Pernambucano. Como fonte de dados secundários, foram escolhidos artigos sobre o PEIEX, relatórios de 
gestão e atividades da APEX, bem como, matérias divulgadas pela imprensa. Por fim, para a análise de dados a opção foi pela análise de conteúdo, baseada no sistema de categorias de Bardin (2016).

O campo empírico para execução desse estudo é, portanto, o setor T\&C, contemplando, especialmente, as empresas do Polo têxtil e de confecção do Agreste Pernambucano participantes do PEIEX. A escolha pelo PEIEX se justifica pela relevância para a internacionalização das empresas brasileiras, especialmente as MPME's que são o tipo de empresa mais comum no Polo de Confecções do Agreste pernambucano; e pela abrangência regional do programa, atuando em diversas cidades do agreste pernambucano.

Neste sentido, este artigo contribui do ponto de vista teórico e empírico ao utilizar a perspectiva teórica da visão baseada em instituição, para compreender as interações entre instituição e internacionalização, envolvendo empresas de uma economia emergente que contempla um ambiente institucional distinto (PENG, 2002). No Polo T\&C, foi possível ressaltar o papel das instituições na determinação das trocas econômicas e sociais em função das estruturas formais e informais, que ora agem como impulsionadoras, ora como inibidoras da internacionalização (PENG, 2002). Portanto, analisar o contexto institucional particular da região agreste no setor T\&C, oferece à visão baseada em instituição, novos insights institucionais em um contexto local, para o exame das decisões empresariais pela internacionalização (PENG; KHOURY, 2008). E com isso, possibilita, dentre outras oportunidades, compreender porque as decisões estratégicas de internacionalização, no Polo T\&C permanecem incipientes na região agreste; e a aplicação de políticas públicas de internacionalização e programas de promoção à exportação mais alinhados a localidade e a estrutura institucional existente (NGO et al., 2016). Ademais, enfocar o papel das instituições do país de origem, especialmente em economias emergentes, no processo de internacionalização das empresas, ainda é um assunto emergente, quando comparado ao volume de estudos que se concentram na influência institucional do país de destino. Dessa forma, esse estudo colabora para a permanência da relevância local e global do tema (MONTICELLI et al., 2017; NGO et al., 2016).
Sendo assim, o objetivo de analisar a influência de um programa de promoção à exportação, enquanto instituição formal, no processo de internacionalização das MPMES em uma economia emergente, perpassa, nesse artigo, pela análise do ambiente institucional do Polo de Confecções e pela análise da influência institucional da APEX/PEIEX no processo de internacionalização das MPMEs participantes do programa. Preliminarmente, os principais achados desse estudo estão na existência de instituições formais e informais dentro do Polo de Confecções, mas que tem agido de modo divergente no estímulo à internacionalização. Além disso, foram observadas tanto influências positivas, quanto negativas do programa da APEX que precisam ser melhor avaliadas para a obtenção de melhorias em sua finalidade de exportação.

Esse artigo está estruturado em mais quatro seções, para além desta seção introdutória. A segunda seção contempla o referencial teórico com as perspectivas teóricas das instituições; mas também as dificuldades para internacionalizar e o papel dos programas de promoção à exportação. A terceira, contempla os aspectos metodológicos e perfaz a caracterização do setor T\&C. A quarta, apresenta a discussão e análise dos resultados; e o estudo é finalizado com a quinta seção, que compreende às conclusões, envolvendo também as limitações e sugestões deste artigo.

\section{REFERENCIAL TEÓRICO}

A escola institucional passou por uma evolução desde o seu surgimento no final do século XIX e início do século $X X$, deixando contribuições em diversas áreas das ciências sociais como a economia, sociologia e política. Nos estudos organizacionais, traz o elemento ambiente como uma variável importante para interpretar a realidade organizacional (CARVALHO; VIEIRA, 2003), e ingressa no estudo dos negócios internacionais de modo a complementar as teorias existentes, contemplando ambientes institucionais distintos, como os das economias emergentes, na internacionalização das empresas (PENG; WANG; JIANG, 2008).

Esse estudo procura compreender essas relações dentro de um contexto específico de uma economia emergente, e que se refere, especialmente, ao setor T\&C e a região Agreste de Pernambuco. Com isso, traz novas perspectivas a análise, uma vez que o ambiente institucional pode variar entre diversas 
regiões de um mesmo país e, assim, fornecer novas contribuições empíricas e teóricas ao estudo (NGO et.al., 2016).

\section{Teoria Institucional}

As instituições guiam as ações humanas, pois fornecem as estruturas cognitivas que irão restringir ou permitir a ação. As ações são restringidas por meio de regras e são permitidas ao tornar as ações significativas (LAWRENCE; SHADNAM, 2008). Para North (p.3, 1990) "as instituições são as regras do jogo e as organizações são os jogadores". Ainda segundo North (1990) um dos teóricos da perspectiva da economia institucional, as instituições agem no intuito de minimizar os custos de transação que surgem em decorrência da incerteza presente nas interações sociais. Nesse sentido, as instituições fornecem as condições para que os empreendedores se aventurem no processo de trocas de mercado que por natureza é incerto.

Portanto, é possível reconhecer que as organizações não operam no vácuo, em vez disso, elas lidam com diversas influências externas como as próprias diferenças culturais, os requisitos legais, normas, demandas dos atores envolvidos com os negócios da empresa, como fornecedores, clientes, agências reguladoras, dentre outros (BERTHOD, 2016).

As instituições atuam por meio de três pilares, que são de natureza: regulativa, normativa e cognitiva, cujos quais proporcionam estabilidade e dão significado à vida social (SCOTT, 2005). O pilar regulador possui ênfase na fixação de normas e ações de coerção para o controle da organização por meio da força e regularização dos comportamentos. Portanto, a força temor e o oportunismo fazem parte deste pilar, porém é regulado pela existência de normas, seja no âmbito formal de leis ou costumes informais (SCOTT, 2005); o pilar normativo, por sua vez, corresponde a elementos institucionais como os valores e normas, sendo o primeiro, aquilo que é preferível ou desejado, e o segundo, indicam como as coisas deveriam ser realizadas de acordo com o que é legítimo (CARVALHO; VIEIRA, 2003). Esse pilar busca compreender se as ações organizacionais são motivadas pelas pressões das normas e dos valores que no decorrer do tempo foram internalizadas pelos indivíduos, tornando-se uma obrigação social; por fim, o pilar cognitivo é formado pelas normas que constituem a realidade e onde os significados são construídos. Esse pilar apoia-se em crenças e pressupostos profundamente estabelecidos no ambiente social (SCOTT, 2005).

Uma outra compreensão importante dentro do estudo das instituições, é que as empresas competem não só por recursos e clientes, mas também por poder político e legitimidade institucional, tornando-se isomórficas com o ambiente para obtenção deste fim. Segundo Dimaggio e Powell (1983), o isomorfismo pode ocorrer por meio de três mecanismos. O primeiro é o coercitivo, que é uma mudança que resulta das pressões formais e informais, como força, persuasão, direcionadas às organizações. O segundo é o normativo, traduz-se no âmbito da profissionalização e compartilhamento de normas e conhecimentos com os demais. E o terceiro, é o mimético que leva em consideração a questão da incerteza para a adoção pela organização de práticas semelhantes às outras organizações, no intuito de minimizar as incertezas e os riscos.

Tomando como base os conceitos mencionados anteriormente, é possível observar a relação existente entre os pilares de apoio preconizados por Scott (2005), com o isomorfismo institucional (DIMAGGIO; POWELL, 1983) e a base de legitimidade presente em cada uma delas (MEYER; ROWAN, 1977). Sendo assim, o pilar regulador ao se estabelecer por meio de regras e leis, conduz a sociedade e organizações a um comportamento isomórfico coercitivo em busca de uma legitimidade legalmente sancionada (SCOTT, 2005). Enquanto que o pilar normativo, que condiciona o comportamento devido a obrigação social, baseada nos valores e expectativas sociais, resulta no isomorfismo normativo em busca da legitimidade moralmente governada (SCOTT, 2005). Por fim, o pilar cognitivo é composto pelo o que é socialmente construído, portanto, são práticas tidas como certas e compartilhadas, remetendo a um comportamento isomórfico mimético, sendo o meio pelo qual os atores sociais buscam a legitimidade amparados na aceitação cultural (SCOTT, 2005).

A teoria institucional e especialmente o neoinstitucionalismo embasaram a visão institucional de gestão estratégica que intervém no ambiente dos negócios internacionais e que será tratado na seção seguinte. 


\section{Visão Baseada na Instituição}

A visão baseada na instituição proporcionou valiosas contribuições à disciplina de estratégia (PENG, 2002; PENG et al., 2009), principalmente, ao considerar as relações complexas e mutáveis entre instituições e organizações, e compreender as escolhas estratégicas das empresas como resultado dessa interação (PENG, 2002). Essa visão foi integrada ao campo da estratégia dos negócios internacionais (PENG; WANG; JIANG, 2008) após os autores perceberem que as instituições são importantes no processo de internacionalização das empresas, especialmente, em economias emergentes, onde as instituições são mais voláteis, visto que há um processo maior de transições institucionais (PENG et al., 2009).

Ao analisar o desempenho internacional das empresas, os autores (PENG et al., 2009; PENG; WANG; JIANG, 2008) propuseram uma integração entre as três visões: a visão baseada em instituição, a visão baseada em recursos (BARNEY, 1991) e a visão baseada na indústria (PORTER, 1980). Com isso, as instituições passam a compor o chamado tripé da estratégia, que agora considera a importância das instituições no processo de internacionalização das empresas, especialmente de economias emergentes. As empresas dessas economias possuem um alto nível de incerteza em seu contexto institucional, logo, enfrentam dificuldades para encontrar os parâmetros que possam orientar as suas decisões estratégicas (XU; MEYER, 2013) aumentando a importância das instituições formais.

As estruturas institucionais contemplam as instituições formais (regras, políticas, contratos econômicos, leis); e as instituições informais (normas, aspecto cultural, ética).

Essas instituições possuem caráter compensatório, pois na ausência de uma instituição formal forte, as instituições informais tomam seu lugar, no intuito de reduzir as incertezas causadoras dos custos de transação. Por fim, no processo de internacionalização, são as estruturas formais que guiarão as escolhas dos agentes, seja no intuito de promover a internacionalização, de impedi-la ou ainda, agir de maneira indiferente (MONTICELLI et al., 2017). Portanto, nesse artigo, apenas a instituição formal do país de origem será considerada.
Instituições Formais

As instituições formais do país de origem possuem um impacto profundo na estratégia global das empresas (BEYER; FENING, 2012), portanto, são consideradas componentes centrais dos sistemas de negócios e inovação, desempenhando um importante papel na manutenção da vantagem competitiva das empresas no exterior, como também, na influência dos processos cognitivos gerenciais e permitindo ou restringindo a aquisição e a implantação de recursos e capacidades estratégicas para uma melhor relação entre os atores no mercado externo (MARANO et al., 2016; CUERVO-CAZURRA, 2011).

As instituições formais compreendem as regras e padrões que foram codificados e que por sua vez, guiarão os comportamentos sociais por meio de estruturas regulatórias, políticas e econômicas (NORTH, 1990), inclusive para mercados internacionais (MARANO et al., 2016).

As instituições formais domésticas influenciam na internacionalização das empresas, tornando-se crucial nos seguintes pontos: a) moldar a mentalidade geral dos gerentes locais para os negócios internacionais; b) atuar como incentivador ou inibidor dos procedimentos necessários para exportação; c) determinar a estrutura de custos e preços das empresas; d) afetar o grau de risco e incerteza nas transações comerciais internacionais; e e) incentivar as empresas para entrar nos mercados internacionais (NORTH, 1990; NGO et al., 2016).

Contudo, existem dificuldades de nível institucional e interno às organizações que podem funcionar como inibidoras de um processo efetivo de internacionalização, especialmente, quando se trata de empresas de economia emergente. $\mathrm{Na}$ seção seguinte, essas dificuldades são melhor explicitadas.

\section{Dificuldades para Internacionalização}

Apesar dos benefícios provenientes da internacionalização, as empresas enfrentam também, diversas dificuldades e ameaças decorrentes tanto do ambiente interno, quanto do ambiente externo à empresa (PROZCZINSKI; STEINBRUCH, 2014; MARANO et al., 2016; CAO, 2012). Essas dificuldades são maiores, 
especialmente, para as empresas localizadas em economias emergentes como é o caso do Brasil devido às condições específicas que acabam afetando no processo de internacionalização das empresas (CAO, 2012; CUERVO-CAZURRA, 2012).

Essas condições específicas no que se refere ao ambiente externo, está presente em quatro diferentes contextos, segundo Prahalad e Mashelkar (2010). O primeiro é o social, caracterizado por níveis baixos de desenvolvimento social, saúde, renda e educação. O segundo é o políticoregulatório, destacando-se a instabilidade devido ao risco-país e o custo-Brasil. O terceiro é a geografia dos países em desenvolvimento, com predominância de infraestrutura precária, gerando maiores custos para as empresas. E o quarto e último contexto é o econômico, refere-se ao mercado de capital, sistema simples de inovação e fornecedores menos desenvolvidos.

De um modo geral, as economias emergentes possuem uma fraca estrutura institucional (WRIGHT; FILATOTCHEV; HOSKISSON, 2005). Mas também, características do ambiente interno podem funcionar como impeditivo para que as empresas de economias emergentes busquem os mercados internacionais, como as relacionadas aos recursos tangíveis e intangíveis da empresa (CAO, 2012).

As dificuldades de adentrar em um novo mercado, são muito maiores para as MPMEs, decorrentes, na maioria das vezes, do seu porte e falta de recursos tangíveis, mas também falta de experiência dos seus gestores, desconhecimento dos mercados, baixo volume de produção, ausência de mão de obra capacitada, dentre outros. Tudo isso, tem comprometido as iniciativas de internacionalização desse grupo de empresas (SEBRAE, 2015; RECKLIES, 2001; SPERS et al., 2008; GUIMARÃES; AZAMBUJA, 2017).

Ainda assim, empresas de maior e menor porte nas economias emergentes, vem utilizando as dificuldades mencionadas anteriormente, como incentivos para buscar os mercados externos. Nesse sentido, tem havido investimentos recentes em educação profissional, uma nova geração com habilidades linguísticas e de experiência no exterior (CARNEIRO; BAMIATZI; CAVUSGIL, 2018). Portanto, muitas empresas têm investido no exterior, para obter ativos estratégicos e evitar as falhas institucionais do país de origem (CUERVO-CAZURRA, 2012; CAO, 2012).
No Brasil para incentivar as empresas a internacionalizarem suas operações, surgem os Programas de Promoção à Exportação, que integram políticas governamentais destinadas a auxiliar a atividade de exportação das empresas (GENÇTURK; KOTABE, 2001).

\section{Programas de Promoção à Exportação}

O governo de países desenvolvidos e emergentes tem desenvolvido programas de assistência à exportação que tem como objetivo fundamental, servir como recurso externo às empresas de modo a fornecer informações vitais para um desempenho efetivo no mercado externo (GENÇTURK; KOTABE, 2001).

Sendo assim, os programas de promoção à exportação reduzem a incerteza e o risco de mercado e de possíveis atitudes oportunistas das empresas localizadas no exterior, tudo isso ao fornecer informações de mercado e coordenar atividades que facilitem as transações comerciais entre os países (KÖNIG, 2016).

Em termos gerais, eles podem ser definidos como "medidas públicas destinadas a auxiliar a atividade de exportação das empresas, desde o aconselhamento, incentivos fiscais e financiamento de exportações, até feiras comerciais e vendas" (GENÇTURK; KOTABE, 2001. p. 51). Não obstante, os programas têm servido de apoio ao desenvolvimento de suas economias (KÖNIG, 2016).

Outro ponto relevante, é que esses programas surgem também como facilitadores das MPMEs que representam uma parcela significativa da economia mundial, mas sofrem com a falta de conhecimento sobre o tema e com as diversas dificuldades inerentes à sua constituição (SERINGHAUS; BOTSCHEN, 1991).

Mas para reduzir as dificuldades e incertezas das MPMEs, o governo brasileiro tem fornecido apoio e financiamento para as empresas exportadoras ou que possuem potencial para exportação. Para isso, órgãos como a APEX, tem desenvolvido diversas ações de promoção comercial e valorização dos produtos e serviços brasileiros no mercado externo e conduzido programas como o PEIEX dentro de diversos setores potenciais. 


\section{METODOLOGIA}

Tomando como ponto de partida o objetivo da presente pesquisa, qual seja, identificar como um programa de promoção a exportação, enquanto instituição formal, influencia no processo de internacionalização das MPMEs de uma economia emergente, considera-se a metodologia de pesquisa qualitativa a mais adequada, e como estratégia de pesquisa, optou-se pelo estudo de casos múltiplos. Em relação a coleta de dados, foram utilizadas fontes primárias e secundárias e, por fim, para a análise de dados foi realizada a análise de conteúdo baseada no sistema de categorias de Bardin (2016).

A pesquisa qualitativa torna-se pertinente, uma vez que ela procura compreender como a realidade ocorre dentro de determinado contexto e como é construída socialmente (GUBA; LINCOLN, 2005). Considerando essa multiplicidade, compreende-se ser adequada a estratégia de estudo de caso para a presente pesquisa, pois permite o conhecimento de características particulares de culturas e países, como os de economias emergentes (ELG; GHAURI; TARNOVSKAYA, 2008) e a compreensão dos fenômenos sociais complexos relacionados com o contexto em que estão inseridos, especialmente em negócios internacionais, pela diversidade de países e situações históricas envolvendo esse processo (PIEKKARI; WELCH; PAAVILAINEN, 2009).

A pesquisa é caracterizada ainda, como um estudo de casos múltiplos, ou seja, que contempla dois ou mais sujeitos e organizações, não buscando necessariamente compará-los, mas antes, analisando o objeto de estudo de forma particular (TRIVIÑOS, 1987). Dessa forma, o estudo de casos múltiplos oferece resultados mais convincentes tornando-se mais robusto (YIN, 2001).

A coleta de dados ocorreu tanto por fontes secundárias, como artigos que contemplam a instituição pesquisada; relatórios de gestão e desempenho da APEX em nível nacional, do período de 2009 a 2018, acessíveis no portal da agência; relatórios de atividades, do período de 2009 a 2018, disponibilizados pelas instituições responsáveis pelo PEIEX que desenvolveram tal tipo de documento, a exemplo do ITEP; matérias divulgadas pela imprensa como no portal de notícias da globo (G1), do MDIC, da AD DIPER e no site das instituições que operam o
PEIEX; também foram utiizados estudos de competitividade setorial da ABIT, IEMI e SEBRAE-PE. Quanto por fontes primárias, por meio de entrevistas semiestruturadas com pelo menos dois tipos de atores: i) empresários e/ou tomadores de decisão das empresas participantes do projeto; e ii) representantes do PEIEX na região, seja coordenadores, técnicos extensionistas ou monitores.

Com isso, foi possível acessar as diferentes perspectivas sobre o fenômeno investigado, compondo um corpus de 9 entrevistas, sendo 5 compostas pelas empresas objeto do estudo de caso, e 4 compostas por representantes do PEIEX. As entrevistas semiestruturadas dispõem de um roteiro com questões pré-estabelecidas e baseadas em teorias pertinentes aos objetivos e ao referencial teórico da pesquisa. E tem como grande vantagem, a flexibilidade de alteração da ordem das questões e incremento de novas (GODOY, 2006). Como critério de rigor científico, foi utilizado a triangulação dos dados primários e secundários, que ajudou a enriquecer a compreensão do fenômeno estudado (PAIVA; LEÃO; MELLO, 2007).

Por fim, na análise de dados, optou-se pela análise de conteúdo (AC) baseada no sistema de categorias, que visa compreender a construção de significado que os indivíduos externalizam na fala (SILVA; GOBBI; SIMÃO, 2005). Para tanto, utiliza-se procedimentos sistemáticos na descrição de conteúdo que visa obter indicadores para inferir conhecimentos (BARDIN, 2016). As categorias de análise foram elaboradas com base na fundamentação teórica, utilizada na formação do roteiro de questões e para a análise e discussão dos resultados, são elas: Caracterização dos casos (história, relevância para o setor); Papel e Influência da Instituição Formal (papel e influência da instituição, importância para o Setor T\&C); e Ambiente Institucional (relação com a instituição formal; fatores institucionais que afetam o desempenho internacional; isomorfismo no setor; instituição informal). Conforme demonstrado na Tabela 1. 
Tabela 1 - Categorias de Análise utilizadas para roteiro de entrevistas

\begin{tabular}{|c|c|c|}
\hline Categorias & Subcategorias & Referências \\
\hline Caracterização & $\begin{array}{l}\text { História; relevância } \\
\text { para o setor T\&C. }\end{array}$ & $\begin{array}{l}\text { Dornelas, 2016; } \\
\text { Gençturk; Kotabe, } \\
\text { 2001; CNI, 2019; Site } \\
\text { das instituições }\end{array}$ \\
\hline $\begin{array}{c}\text { Papel e } \\
\text { Influência da } \\
\text { Instituição } \\
\text { Formal }\end{array}$ & $\begin{array}{l}\text { Papel e influência da } \\
\text { instituição formal; } \\
\text { importância para o } \\
\text { setor T\&C. }\end{array}$ & $\begin{array}{l}\text { Beyer; Fening, 2012; } \\
\text { Marano et al., 2016; } \\
\text { Cuervo-Cazurra, } \\
\text { 2011; Ngo et al., } \\
\text { 2016; Peng; Wang; } \\
\text { Jiang, 2008; Site das } \\
\text { Instituições. }\end{array}$ \\
\hline $\begin{array}{l}\text { Ambiente } \\
\text { Institucional }\end{array}$ & $\begin{array}{lr}\text { Relação com } & \text { a } \\
\text { instituição formal; } & \text { fatores institucionais } \\
\text { que afetam } & \text { desempenho } \\
\text { internacional; } & \\
\text { isomorfismo no } \\
\text { setor; instituição } \\
\text { formal. }\end{array}$ & $\begin{array}{l}\text { Peng; Wang; Jiang, } \\
\text { 2008; Scott, 2005; } \\
\text { Dimaggio; Powell, } \\
\text { 1983; Meyer; Rowan, } \\
\text { 1977; Peng, 2002; } \\
\text { Peng; Khoury, 2008; } \\
\text { Peng et al., 2009; Xu; } \\
\text { Meyer, 2013; Cuervo- } \\
\text { Cazurra, 2012; North } \\
\text { (1990). }\end{array}$ \\
\hline
\end{tabular}

Fonte: Elaboração Própria.

A análise dos dados dessa pesquisa se desenvolveu em três etapas, conforme Bardin (2016). A primeira, é a pré-análise onde as pesquisadoras sistematizaram as ideias iniciais, escolheram os documentos do corpus da análise e formularam os objetivos. A segunda, é a exploração do material, nessa etapa o material coletado foi dividido por enumeração e classificados e agregados às categorias temáticas estabelecidas previamente. E por fim, o tratamento de resultados, onde foi realizado a interpretação do material coletado das diversas fontes, respaldadas no referencial teórico.

\section{O Setor Têxtil e de Confecção}

O setor têxtil e de confecção é considerado um dos mais tradicionais e complexos na atualidade. No Brasil, esse setor representa a quarta maior cadeia produtiva integrada e verticalizada do mundo e a maior do hemisfério ocidental (CNI, 2017).

Embora o Brasil esteja entre os maiores produtores mundiais do setor T\&C, a sua participação mundial ainda é tímida, possuindo apenas 0,3\% da participação (em valor exportado) (CNI, 2017).

Realizando um recorte geográfico para o Estado de Pernambuco, é possível observar um dos principais Polos do setor T\&C, que está localizado na região agreste do Estado e que tem como principais cidades: Santa Cruz do Capibaribe, Toritama e Caruaru. Além destas, outras sete cidades atuam no referido setor. O Polo é constituído por cerca de 18 mil empresas, entre formais e informais e é formado predominantemente por micro, pequenas e médias empresas. Além disso, emprega mais de 100 mil pessoas que representam a maior parte da produção do Estado.

Os três principais municípios do Polo, possuem resultados de exportação ainda muito baixos, mantendo a balança deficitária. Silva (2011) identificou como um dos maiores entraves às exportações locais de confecção, a questão da informalidade. Apesar da informalidade na produção funcionar bem no Brasil, o mesmo não ocorre nas tratativas para exportação devido ao rigor da fiscalização alfandegária (SILVA, 2011).

O autor aponta ainda, um outro aspecto do Polo, que é a força da concorrência chinesa que consegue oferecer preços mais baixos do que os oferecidos pelas empresas do Polo de confecções, que corrobora com os apontamentos feitos pelo SEBRAE (2013). Portanto, um dos principais desafios do Polo é o desenvolvimento de políticas públicas, com vistas a dar suporte e alongar a vida das MPMEs, fomentando seu crescimento e sustentabilidade, principalmente diante da competitividade nacional e internacional (DIEESE, 2010). É nesse sentido que o PEIEX foi pensado para a região agreste de Pernambuco, com vistas a capacitar as micro, pequenas e médias empresas da região.

Tendo em vista as perspectivas teóricas utilizadas para esse estudo, serão expostos no tópico seguinte, a descrição dos casos e a análise dos resultados.

\section{RESULTADOS E DISCUSSÃO}

\section{Descrição dos Casos}

\section{Agência Promotora de Exportação e o Programa PEIEX}

A Agência Brasileira de Promoção de Exportações e Investimentos (APEX-Brasil), possui como objetivo, executar junto ao poder público, políticas de promoção de exportações, ações para promoção de investimentos, gerar empregos e apoiar às empresas de pequeno porte, conforme as políticas nacionais de desenvolvimento. As ações da agência ocorrem por meio de missões prospectivas e comerciais, 
rodadas de negócios, apoio à participação de empresas brasileiras em feiras internacionais, organização de visitas de compradores estrangeiros para conhecer a estrutura de produção brasileira, com vistas ao fortalecimento da marca Brasil.

De forma a melhor se aproximar das empresas brasileiras, a agência utiliza de alguns projetos relevantes para aumentar a capilaridade no Brasil, dentre eles, destaca-se o Programa Extensão Industrial Exportadora (PEIEX). Esse programa tem como principal objetivo a preparação de micro e pequenas empresas para atuar no comércio exterior de forma planejada e segura.

O PEIEX ajuda a estimular a competitividade e promover a cultura exportadora nas empresas por meio da qualificação dos empresários iniciantes em comércio exterior. Esse programa prioriza o atendimento às empresas que possuem potencial para inserir-se no mercado internacional, privilegiando assim, setores com potencial para a exportação.

O programa existe em todas as regiões do país em parceria com instituições de ensino ou federações de indústria. Um dos locais de atuação do PEIEX é o Agreste Pernambucano, que desde 2009 trabalha na capacitação de MPMEs em diversos municípios do interior do Estado que compõe o Polo de Confecções, mas prioritariamente, tem atendido aos municípios de Caruaru, Santa Cruz do Capibaribe e Toritama.

O programa já ocorreu na região em três ciclos diferentes. O primeiro, junto ao Instituto de Tecnologia de Pernambuco (ITEP); o segundo, em parceria com a UFPE; e o terceiro e atual, com a Associação Caruaruense de Ensino Superior (ASCESUNITA).

\section{Caracterização das Empresas}

\section{Empresa A}

É uma empresa de pequeno porte que produz moda praia infantil na cidade de Santa Cruz do Capibaribe. O interesse da empresa pelo mercado internacional surgiu após a associação com a ASCAP (Associação Empresarial de Santa Cruz do Capibaribe) que thes apresentou à outras instituições como o SEBRAE (Serviço Brasileiro de Apoio às Micro e Pequenas Empresas). Por meio do SEBRAE a empresa foi apresentada ao PEIEX e, também, participou da sua primeira feira internacional, a ExporComer. Além dessa experiência, a empresa já vendeu informalmente para Portugal, por meio de atravessador, e atualmente, exporta para o Chile ainda que pontualmente e em pouca quantidade.

\section{Empresa B}

Empresa de pequeno porte e que atua na produção de moda infantil na cidade de Surubim-PE. A convite do SEBRAE, participou do EINNE (Encontro Internacional de Negócios do Nordeste), onde conheceu a AD DIPER que o indicou para participar da curadoria da ABIT, que, por sua vez, o apresentou ao PEIEX. Atualmente, a empresa encontra-se preparada para atender toda a América do Sul até o Caribe e pretende ter sua primeira experiência internacional em três anos. Enquanto isso, busca focar nas demandas internas pelos seus produtos.

\section{Empresa C}

É uma empresa de médio porte, localizada em Santa Cruz do Capibaribe-PE e especializada no seguimento surfwear. Foi por meio da ASCAP e do SEBRAE que a empresa tomou conhecimento do PEIEX e resolveu participar da capacitação. Em 2018 a empresa teve a oportunidade de realizar vendas para países da América do Sul, oportunizado por meio de uma trader. Apesar do valor pequeno, o empresário considera que a experiência foi bastante significativa, porém, seu foco atual é atender ao mercado interno e só então, partir para um segundo passo que seria a exportação.

\section{Empresa D}

A empresa é especializada em moda praia e caracteriza-se como de pequeno porte. A sua primeira exportação ocorreu após participar de uma rodada de negócios em Recife. Desde então, a empresa participa de exposições em feiras na Espanha, França e Panamá. Além desses, já exportou para países como Estados Unidos, Portugal e Uruguai. Também foi por meio de sua participação em feiras e rodadas de negócios que conheceu o PEIEX e decidiu participar das capacitações como forma de aperfeiçoamento. Atualmente as exportações são realizadas esporadicamente.

\section{Empresa $E$}

A empresa é de médio porte, especializada em camisaria masculina e funciona em Caruaru há mais de dez anos. Seu interesse pelo mercado 
internacional foi despertado pelo PEIEX que Ihes foi apresentado em uma rodada de negócios do SEBRAE. Contudo, a empresa decidiu por não seguir com as capacitações do programa para dedicar-se ao mercado interno, e apenas investir em outros mercados quando estiver bem estabelecido no país de origem.

\section{Análise dos Resultados}

Ambiente Institucional do Polo de Confecção

Esforços governamentais, na instituição de programas como o PEIEX, surgiram no setor no intuito de combater a concorrência e criar uma expertise de exportação nas empresas da região. Essas instituições formais objetivam sobretudo a disseminação de regras e regulamentos que são comportamentos comuns desse tipo de instituição.

O setor têxtil brasileiro conta com um ambiente institucional repleto de instituições formais que buscam direcionar as empresas em suas atividades (NORTH, 1990; PENG, 2009). Com o Polo de confecções do agreste não é diferente, foi identificado instituições de nível nacional, estadual e municipal que se propõem a agir nesta frente apoiando as empresas tanto para o mercado nacional, quanto internacional. A APEX na institucionalização do PEIEX é uma instituição federal e que foi considerada pelos entrevistados como de fundamental importância na promoção à exportação das empresas do Polo, e bastante lembrada como idealizadora e apoiadora de diversas feiras que congregam compradores internacionais.

Configurando-se na região como um importante componente dentro do domínio regulatório, no estabelecimento de normas e regras para um comportamento internacional dos empresários (SCOTT, 1995).

As instituições parceiras da APEX na operacionalização do PEIEX, trabalham no apoio às empresas em particularidades que o Programa, sozinho, não consegue alcançar. Elas também foram citadas como fundamentais, tanto no apoio às empresas junto ao PEIEX, quanto de modo individual, atuando ativamente dentro das organizações com consultorias, cursos e divulgação de feiras e eventos.

No nível nacional, foi citada a Associação Brasileira da Indústria Têxtil e de Confecção (ABIT) e
- Serviço Brasileiro de Apoio às Micro e Pequenas Empresas (SEBRAE), sendo esta última citada de forma unânime por todos os entrevistados, como instituição importante na prestação de consultorias, disposição de cursos de aperfeiçoamento e capacitações. No âmbito Estadual, foi citada a Agência de Desenvolvimento Econômico de Pernambuco (AD DIPER); enquanto que em nível Municipal, a Associação Empresarial de Santa Cruz do Capibaribe (ASCAP) foi a mais referendada entre os entrevistados.

É importante ressaltar, que os empresários entrevistados tomaram conhecimento do PEIEX por meio de algum desses parceiros institucionais. O que demonstra que essa parceria da APEX com as entidades já reconhecidas e que possuem credibilidade junto aos empresários do Polo, remete a um apelo da agência por legitimidade institucional em prol da aceitação do programa pelos empresários da região, reduzindo o risco de sua atuação junto a este público (DIMAGGIO; POWELL, 1983). Como é possível observar na fala do entrevistado a seguir: "Tanto é que quando tinham essas reuniões da APEX/PEIEX né? Sempre vinha alí AD DIPER, sempre vinha o SEBRAE [...] e dizia: ó, vamos fazer, ó estamos incentivando a ação tal" (Monitor do PEIEX da Fase II).

Não obstante, foi possível observar uma pressão institucional coercitiva das instituições parceiras, por meio de convites e cobranças aos empresários para participar do PEIEX ou de eventos ligados ao comércio exterior (DIMAGGIO; POWELL, 1983).

Além da participação institucional do governo numa tentativa de integrar e regular o setor por meio das instituições formais que promovem 0 programa, foi possível observar, entretanto, condições do contexto político, geográfico e econômico que afetam o ambiente institucional do Polo de Confecções e tem funcionado como inibidores de uma decisão efetiva dos empresários no que tange às exportações (CUERVO-CAZURRA, 2012).

No que se refere às características político/regulatórias foram citados: forte burocracia do Estado, carga tributária elevada, altas exigências do governo, informação mal distribuída para a classe empresarial, ausência de barreiras para importação (especialmente China), insegurança decorrente das recentes transições governamentais e sobreposição de iniciativas do governo para o comércio exterior. 
No contexto econômico, a volatilidade cambial e a crise econômica foram os aspectos mais citados. No geográfico, a infraestrutura precária do Estado e a logística deficiente e cara se destacaram. E no nível social, foram citadas: a falta de segurança e educação precária.

Mas há também, aspectos ligados ao ambiente interno da organização que podem dificultar os investimentos nos mercados internacionais. Nesse sentido, foram identificados durante a entrevista: a ausência de conhecimento de outros idiomas e de profissionais com esta habilidade na organização, falta de recursos financeiros, baixo volume de produção para atender outros mercados, empresa familiar enrijecida e foco na produção para o mercado interno.

Essas dificuldades e ameaças decorrentes tanto do ambiente interno, quanto do ambiente externo às empresas, costumam ser maiores em economias emergentes como o Brasil, devido às condições específicas e frágeis que atuam no contexto social, político-regulatório, geográfico, econômico (JANKOV et al., 2002; CUERVO-CAZURRA, 2012), e na condição de ser uma empresa de micro, pequeno ou médio porte, principalmente no contexto de economia emergente (SPERS et al., 2008).

Contudo, identificou-se na realidade do Polo, alguns aspectos que estão começando a mudar, de modo a minimizar essas dificuldades resultantes do contexto institucional. Essas mudanças têm sido influenciadas pela segunda geração, estimulada pelo ensino superior, e que vem gerando um despertar na mentalidade dos seus pais para as novas possibilidades de negócios.

O que demonstra a presença do pilar de apoio cognitivo formado pelas normas que constituem a realidade e onde os significados são construídos (CARVALHO; VIEIRA, 2003). E resultando em pressões normativas no âmbito da profissionalização da segunda geração, e no consequente compartilhamento de normas (DIMAGGIO; POWELL, 1983).

Além disso, a recente leva de empresários da primeira e segunda geração que estão visitando o exterior, tem fornecido um percurso de descobertas de um mundo antes visto como impossível e assustador, e que agora tem despertado o interesse dos empresários para novas oportunidades em outros mercados. O Monitor do PEIEX da Fase II comenta: "[...] a gente tem relatos de empresários que participou de viagens internacionais, que quando vai nas gôndolas das empresas observa que o produto dele é melhor do que o que está sendo vendido e se questiona, poxa, porque esse produto tá aqui e o meu não tá?".

Sendo assim, uma explicação teórica é possível, quando apesar das dificuldades presentes no ambiente institucional, as empresas de economias emergentes, sejam de maior ou menor porte, utilizam-se dos obstáculos como estímulos para superarem as barreiras impostas no país de origem e buscarem os mercados externos (CAVUSGIL, 2018; CUERVO-CAZURRA, 2012). Os investimentos dos gerentes em diversas habilidades linguísticas e de experiência no exterior, tem sido uma das formas de eliminar as dificuldades institucionais do país de origem (CARNEIRO; BAMIATZI; CAVUSGIL, 2008).

Não obstante, foi identificado no ambiente institucional do Polo de Confecções, um aspecto bastante forte na região que é a questão cultural, constituindo-se como uma instituição informal que tem influenciado na decisão dos empresários sobre internacionalizar (PENG et al., 2009). Um exemplo é a informalidade muito comum na região agreste, que tem limitado o desenvolvimento tanto em âmbito nacional, quanto internacional, já que diversas exigências legais não são cumpridas, impedindo uma negociação efetiva com outros mercados.

Para piorar, a informalidade na região, muitas vezes, é associada ao empreendedorismo, supervalorizando esse modus operandi como um ato heroico, uma atitude de garra e perseverança, mas que é prejudicial aos empresários ao longo prazo e também ao país pelo não recolhimento dos tributos devidos. Essa atitude tem reforçado um comportamento isomórfico mimético, pois as empresas repetem esse comportamento por perceberem que é algo natural e legítimo na região, sendo a melhor forma de desvencilhar-se das incertezas inerentes ao início de qualquer negócio (DIMAGGIO; POWELL, 1983).

Como consequência, esse aspecto cultural tem sido um fator limitador do processo de internacionalização, já que para se internacionalizar é preciso tornar-se formal, e isso, muitos empresários não estão dispostos, pois afeta diretamente na sua competitividade em preço na região. Como é relatado pela Coordenadora da fase 
II do PEIEX: " a gente sabe que um empecilho do empresário tem a ver com a cultura, ele quer vender aqui, ele não quer adaptar o produto, ele não quer ter custo para enviar o produto pro exterior..."

As instituições informais compreendem as normas socialmente aceitas e o aspecto cultural e possuem caráter compensatório, pois na ausência de uma restrição formal forte, as instituições informais tomam seu lugar, no intuito de reduzir as incertezas (PENG et al., 2009). Na seção seguinte, será explicitado, mais precisamente, sobre a influência da instituição formal, O PEIEX, na internacionalização das empresas do setor T\&C.

\section{Influência da Instituição Formal na Internacionalização das MPMEs}

Esse estudo permitiu constatar, com base nas entrevistas e nos dados secundários, um importante papel do programa PEIEX na condução de estímulos e capacitações para a abertura de consciência dos empresários, com vistas ao mercado internacional. Mas, seus esforços, nos últimos onze anos, ainda não têm acarretado na internacionalização de fato, muito menos em uma cultura exportadora no setor T\&C.

O PEIEX tem atuado no Polo de confecções de modo conjunto à outras instituições formais de apoio, configurando-se como um projeto que busca a integração do setor, porém, percebe-se que a legitimidade da instituição não foi conquistada, pois ainda há muita desconfiança dos empresários sobre o processo de internacionalização e também frustrações decorrentes de iniciativas anteriores da própria instituição na região.

Segundo os representantes do PEIEX, a APEX sugere que sejam atendidas as empresas mais estruturadas que possuam um maior potencial de exportação, embora a própria agência e parceiros institucionais também induzam listas de empresas que não possuem o mínimo interesse ou mesmo condições mínimas de exportar.

Essa atitude configura-se como contraditória, pois vai de encontro com às especificações formais da APEX e gera dispêndios de recursos financeiros, de tempo e de esforços das equipes do PEIEX. Além disso, a imagem institucional da APEX acaba perdendo legitimidade, afastando empresas potenciais da rota de capacitação. O empresário B reforça essa preocupação: "[...] então, às vezes, a seleção tem que ser criteriosa, de dizer assim, bicho, você tem perfil, mas você quer? Porque ter perfil e não querer é a mesma coisa[...]".

O programa tem sido visto pela maioria dos entrevistados como importante, principalmente ao desmistificar a respeito da exportação, no esclarecimento sobre os processos que conduzem à internacionalização, na entrega de possibilidades de mercados potenciais para os produtos dessas empresas, promoção e apoio em feiras e rodadas de negócios, e adaptações em processos e produtos. Nesse sentido, a empresária A relata: "O PEIEX que esteve aqui e fez um trabalho muito bacana dentro da nossa empresa, até porque eles não pegam só a parte de internacionalização, eles abrangem a empresa como um todo". Esses benefícios também foram encontrados no estudo de Dornelas (2016) e Leonidou, Katsikeas e Piercy (1998).

As instituições formais como a APEX na formatação do PEIEX, possui um esforço significativo junto às empresas em prol de sua internacionalização, e que podem contribuir em algumas frentes: a) ao moldar a mentalidade geral dos gerentes locais para os negócios internacionais; b) atuar como incentivador ou inibidor dos procedimentos necessários à exportação; c) determinar a estrutura de custos e preços das empresas; e d) afetar o grau de risco e incerteza das transações comerciais internacionais (NORTH, 1990; NGO et al., 2016).

Para os representantes do PEIEX, são as empresas de menor porte e que, geralmente, não possuem condições de exportar, que mais tem se beneficiado das capacitações, já que devido ao seu reduzido porte e escasso conhecimento de gestão e processos organizacionais (RECKLIES, 2001; SEBRAE, 2015), o programa pode atuar com orientações válidas e fundamentais para essas empresas, como: necessidade de site, alocação de recursos e equipamentos, questões ambientais, estagiário, dentre outros.

Contudo, algumas críticas também foram dirigidas ao programa, como: a incipiente atenção no quesito comércio exterior, pois há um foco maior nas deficiências organizacionais no aspecto gestão. Isso está atrelado ao recrutamento dos profissionais que irão compor às equipes dos núcleos operacionais, que tem se preocupado mais em recrutar profissionais com competências de gestão, 
que de fato é importante, porém, acabam negligenciando o conhecimento específico para o qual se conduz as capacitações. Nesse sentido, o Monitor da Fase II comenta: "[...] nenhum monitor está habilitado pra isso, porque a gente não é selecionado por ser especialista em ser um negociador internacional, a gente é especialista em alguma atividade ou é administração ou é algum conhecimento de mercado". No estudo de Dornelas (2016) sobre o PEIEX, também foi encontrado a mesma deficiência do corpo técnico de extensionistas, apresentando-se como um problema não só da região agreste de Pernambuco, mas também de outros Estados brasileiros.

Além disso, um outro ponto abordado tanto por representantes da instituição, quanto pelos empresários, foi a divulgação do programa, muitas vezes realizada por políticos que ao se promoverem em cima do programa, prometem feitos milagrosos que na realidade, o PEIEX não se propõe a realizar. Com isso, muitos empresários ficam na expectativa de exportarem rapidamente, o que na maioria das vezes, não se concretiza, já que é um processo deveras lento, causando frustrações em boa parte da classe empresarial.

Nesse sentido, uma outra reclamação dos empresários em relação ao programa, são os poucos resultados práticos que culminem, de fato, em exportação, tornando o programa pouco prático na opinião dos empresários entrevistados. O empresário C comenta: "[...] e as ações do PEIEX pecam muito por isso, ficam muito na teoria e a prática não gera o resultado esperado, não adianta se qualificar e não efetivar vendas [...] então, isso as vezes deixa até boa parte dos empresários daqui frustrados". Como consequência, apesar das empresas reconheceram a importância do programa dentro do setor têxtil e de confecção do agreste, muitos encontram-se resistentes em participar de outras fases do projeto.

Portanto, embora a literatura advogue que os programas de promoção à exportação tenham a função de reduzir a incerteza e o risco de mercado e de possíveis atitudes oportunistas no exterior, por meio da informação (KÖNIG, 2016; NGO et al., 2016), ainda é possível observar uma carência dos empresários de serem assistidos para além da fase de diagnóstico, o que indica uma certa insegurança ou mesmo comodismo dos empresários de seguirem sozinhos. A empresária A explica: " então é importante vir, fazer a capacitação e depois dar uma assistência, né? Porque é feito menino, vai pra escola, se a mãe não tiver em cima da tarefa, ele não faz não".

Esse nível de insegurança e incerteza das empresas do Polo, são características comuns de empresas de economias emergentes, o que aumenta a importância da efetividade das ações de instituições formais na redução de incertezas (PENG et al., 2009; PENG, 2002), sendo esta, uma das atribuições dos programas de promoção à exportação (KÖNIG, 2016).

Assim, percebeu-se que apesar dos benefícios do programa, ele ainda tem contribuído de forma incipiente para o processo efetivo de internacionalização das MPME's do Polo têxtil e de confecção. O que se percebe, são as empresas ainda em um estágio muito inicial, onde a maior influência do PEIEX tem sido moldar a consciência do empresário para o mercado internacional, com informações, participação em feiras e adaptações dos produtos para esses mercados.

Ademais, o PEIEX tem avançado no agreste, no decorrer dos seus onze anos de atuação na região, e identificado algumas dessas deficiências. Inclusive, na fase atual do programa, a APEX colocou como exigência, a filiação a uma instituição de ensino que tivesse um curso voltado ao comércio exterior, o que demonstra um maior interesse com a temática central do programa e que possa produzir resultados mais práticos de exportação.

Porém, ainda que não tenha gerado a ida ou aumento nas vendas para mercados internacionais, adotar uma posição de distância do PEIEX, só tornará ainda mais difícil a preparação das empresas, de seus produtos e o consequente êxito nas exportações. Pois o programa proporciona uma apropriação de conhecimento, aprendizado, e uma rede de relacionamento única, por intermédio em feiras nacionais e internacionais, rodadas de negócios locais e demais eventos (KÖNIG, 2016; GENÇTURK; KOTABE, 2001).

Por fim, pode-se concluir que a formação do programa PEIEX, alterou ainda que de modo singelo, a dinâmica dos negócios dos empresários do setor têxtil e de confecção do Polo do Agreste, das mais diferentes formas. Para as empresas que já haviam atuado de alguma forma no mercado externo, o 
A Influência da Instituição Formal no Processo de Internacionalização das MPMEs em uma Economia Emergente

programa atuou como um reforço em conhecimento, atualizações e networking.

Já para as empresas que não aderiram ao programa, perceberam uma oportunidade de negócio para além das fronteiras do mercado local e que podem acarretar em diversos benefícios como a melhoria da imagem dos produtos têxteis e confeccionados, e diversificação de mercados e riscos. Ademais, para todas as empresas, houveram melhorias na gestão, processos, adaptações de produtos para outros mercados, que gerou, automaticamente, benefícios para o mercado doméstico e consequente melhoria na vantagem competitiva do setor têxtil e de confecção a nível local e nacional. Portanto, entende-se a importância do PEIEX como fundamental para as organizações e suas consequentes escolhas estratégicas de internacionalização (PENG, 2002).

\section{CONCLUSÕES}

Esse estudo se propôs a analisar como um programa de promoção à exportação, enquanto Instituição Formal, influencia na internacionalização das MPMEs em uma economia emergente. Para tanto, foi realizada uma análise do ambiente institucional que permeia o Polo de Confecções do Agreste Pernambucano, bem como, da influência da APEX no âmbito do PEIEX na internacionalização das MPMEs do Polo.

Dessa feita, foi observado no ambiente institucional do Setor Têxtil e de Confecção, instituições formais e informais que agem predominantemente de modo divergente entre si. Enquanto há instituições formais que se demonstram importantes ao tentar integrar-se em apoio ao PEIEX e às empresas do Polo de Confecções em diversas frentes, tem, ao mesmo tempo, instituições formais que vêm agindo por meio de estruturas político/regulatórias, econômica, e geográfica, de modo a inibir possíveis decisões de internacionalização.

Além disso, há instituições informais, dentro do aspecto cultural, que tem servido como inibidor da decisão do empresário pela exportação, e também, como limitadora do desenvolvimento dessas empresas no próprio mercado nacional. O que demonstra uma necessidade por uma maior integração entre as instituições para que venham a convergir em resposta e em apoio, às políticas públicas de promoção à exportação.

Em relação a influência da instituição formal, PEIEX, na internacionalização das MPMEs, foi observado que há uma influência positiva, sobretudo, na transmissão de conhecimentos sobre o processo de internacionalização, nas sugestões de melhorias de produtos e processos e na promoção de feiras e rodadas que resulta em networking para os empresários. Contudo, a internacionalização efetiva ainda não foi obtida, pelo menos com as empresas entrevistadas.

Ademais, algumas críticas também foram direcionadas ao programa, como a incipiente atenção ao comércio exterior no momento da capacitação; forma de divulgação, que muitas vezes inclui interesses políticos; resultados pouco práticos em termos de exportação; e necessidade de uma assistência após a qualificação, na condução das melhorias e adaptações necessárias e nas primeiras vendas internacionais das empresas. Ainda assim, estimula-se a participação das empresas no programa para que os benefícios provenientes dessa instituição sejam devidamente apropriados pelas empresas e contribua para futuros resultados exitosos em termos de exportação.

Sendo assim, foi possível respaldar-se no neoinstitucionalismo (SCOTT, 1995; DIMAGGIO; POWELL, 1983) e na visão baseada em instituição (PENG, 2002; PENG et al., 2009) para compreender este fenômeno, trazendo novas perspectivas do ambiente institucional de uma economia emergente, aplicadas a um contexto específico.

Os resultados desse estudo demonstraram que embora o ambiente institucional doméstico possua um importante papel ao configurar os seus mecanismos cognitivos, normativos e reguladores na promoção a exportação em economias emergentes (NGO et al., 2016), no Polo T\&C, esses mecanismos têm se apresentado mais como inibidores do que facilitadores das exportações. Portanto, essas considerações podem ampliar conceitualmente as demais pesquisas de exportação, com os fatores do ambiente doméstico seja político, econômico ou social que influenciam positiva ou negativamente as decisões estratégicas das empresas pela internacionalização. Essa compreensão torna-se ainda mais interessante ao entender os aspectos externos e também internos de empresas de economias emergentes, devido ao caráter 
transitório e específico do seu ambiente institucional.

Além disso, observou-se uma tendência das empresas do Polo T\&C em superar os aspectos frágeis do país de origem, por meio dos investimentos em educação profissional, em novos idiomas e vivência no exterior.

Não obstante, ao considerar o contexto institucional particular da região Agreste no setor $T \& C$, tendo em vista que o ambiente institucional pode variar não só entre países, mas também, entre diversas regiões de um mesmo país (NGO, 2016), possibilita a formulação de metodologias de programas de promoção à exportação mais assertivas para a localidade.

Além disso, o aperfeiçoamento do domínio regulador no que tange às regras e regulamentos apropriados da instituição APEX e do governo de modo geral, que atue de forma integrada com as instituições presentes no ambiente institucional do Polo, de modo a convergir para resultados positivos de exportação precisam ser melhor definidos. Com isso, possibilita a redução de incertezas relacionadas ao processo de internacionalização no Polo T\&C e estimula um desempenho positivo nos mercados externos.

Para tanto, é primeiramente necessário que o governo por meio da regulação do mercado, realize acordos comerciais, desburocratize, invista cada vez mais em projetos e instituições setoriais, fomente o mercado nacional e internacional, estimule os empresários por meio de políticas públicas a direcionarem suas estratégias empresariais também para outros países e com isso, consiga um resultado positivo no médio e longo prazo.

Por fim, de modo a materializar os achados desse estudo, foi elaborada uma representação do ambiente institucional do Polo T\&C, onde é possível observar as principais instituições formais e informais que tendem a ter uma influência mais positiva (+) ou negativa (-) para a internacionalização das empresas do Polo. Na representação, também foram contemplados o mercado chinês, visto como uma das principais ameaças às empresas do Polo; e as pressões institucionais que ora apresentam influência positiva, ora negativa, a depender do contexto em que elas ocorrem. Conforme exposto na Figura 1.

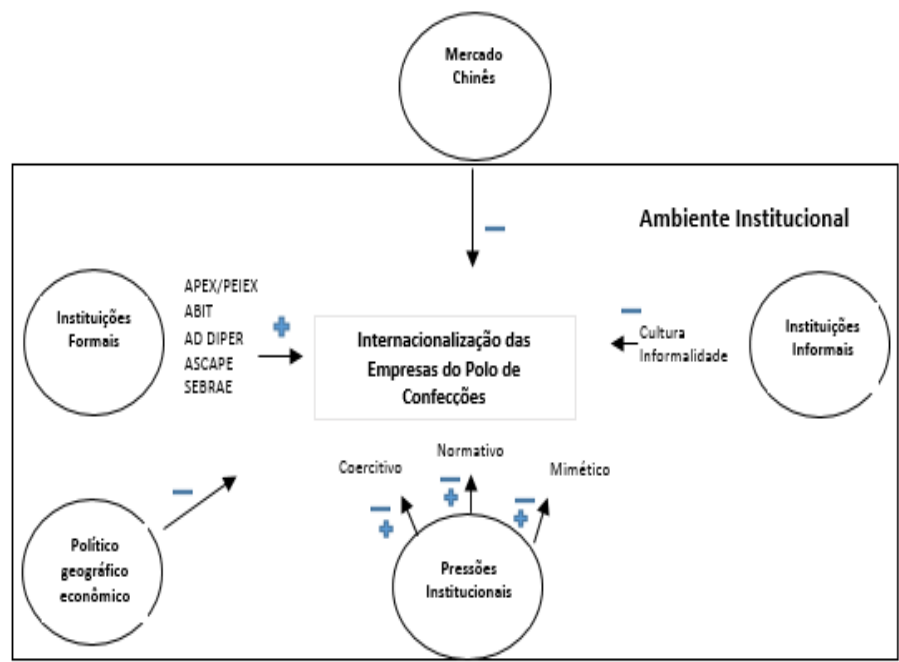

Figura 1 - Ambiente Institucional do Pólo de Confecções Fonte: Elaboração Própria.

Limitações da Pesquisa

As principais limitações dessa pesquisa compreendem o baixo número de entrevistas, nove ao todo, entre empresas e representantes da instituição formal. Sendo uma quantidade pequena se comparada a quantidade de envolvidos no ambiente institucional, incluindo representantes de outras instituições formais parceiras da APEX. Outro fator limitante, foi o sigilo de informações dos representantes do PEIEX, que comprometeu o achado de um maior número de empresas.

\section{Sugestões de Pesquisas Futuras}

De modo a produzir um aprendizado sistemático, sugere-se o uso de mais instituições formais que atuam no setor têxtil e de confecção, a exemplo do SEBRAE e AD DIPER, entidades setoriais, como a ASCAP e, também, buscar entrevistar representantes da APEX que trabalham no núcleo do Estado, para compor um quadro mais completo para análise. Outra sugestão, é considerar para a pesquisa outros setores da economia ainda na região Agreste, para uma análise segmentada e comparativa da influência do PEIEX nos diversos setores e contextos institucionais. Ou ainda, comparar a influência do PEIEX do Agreste com cidades de outros Estados que possuem o programa atuante também no setor T\&C. 


\section{REFERÊNCIAS}

BARDIN, L. Análise de conteúdo. São Paulo: Edições 70, 2011.

BERTHOD, O. (2016). Institutional theory of organizations. In A. Farazmand (Ed.), Global Encyclopedia of Public Administration, Public Policy, and Governance. Springer International Publishing. https://doi.org/10.1007/978-3-319-31816-5

BEYER H; FENING. F. The impact of formal institutions on global strategy in developed vs. emerging economies. Int J Bus Soc 3(15):30-36, 2012.

BORINI, F. M.; RIBEIRO, F. C. ; COELHO, F. P. ; PROENÇA, E. R. . O Prisma da Internacionalização: Um Estudo de Caso. Faces (FACE/FUMEC), v. 5, p. 42-55, 2006.

CAO, M. Y. International Expansion of Emerging Market Multinationals: An Integrated Perspective. International Conference on Innovation and Information Management (ICIIM), 2012.

CARNEIRO, J. M. T.; BAMIATZI, V. ; CAVUSGIL, S. T. Organizational slack as an enabler of internationalization: The case of large Brazilian firms. International Business Review , v. 27, p. 1057-1064, 2018.

CARVALHO, C.; VIEIRA M. Contribuições da perspectiva institucional para análise das organizações: possibilidades teóricas, empíricas e de aplicação. In: CARVALHO, C.; VIEIRA M. Organizações, cultura e desenvolvimento local. Recife: Edufepe, 2003.

CONFEDERAÇÃO NACIONAL DA INDÚSTRIA - CNI. O setor têxtil e de confecção e os desafios da sustentabilidade. Confederação Nacional da Indústria - Associação Brasileira da Indústria Têxtil e de Confecção - Brasília: CNI, 2017.

COSTA, L. F. L. G.; ANEZ, M. E. M. ; MOL, A. L. R. ; DAMASCENO, T. S. A. Escolas teóricas do processo de internacionalização: uma visão epistemológica. CADERNOS EBAPE.BR (FGV), v. 15, p. 960-973, 2017.
Influences of the home country on a firm's global strategy. Global Strategy Journal, 1: 382-386, 2011.

CUERVO-CAZURRA, A. Extending theory by analyzing developing country multinational companies: Solving the Goldilocks debate. Global Strategy Journal, 167, 153-167. 2012. doi:10.1111/j.2042-5805.2012.01039.x

DIAS, A. L. Reflexões e ações para a internacionalização da pequena empresa brasileira. Dissertação de Mestrado - Programa de PósGraduação em Engenharia da Produção - UFSC, 2002.

DIEESE. Diagnóstico do setor têxtil e de confecções de Caruaru e Região. Relatório de Pesquisa. Acesso em: Abril/2019.

DIMAGGIO, P.; POWELL, W. The iron cage revisited: institutional isomorphism and collective rationality in organizational fields. American sociological review, v. 48, p. 147-160, 1983.

ELG, U., GHAURI, P.N., TARNOVSKAYA, V. (2008). The role of networks and matching in Market entry to emerging retail markets. International Marketing Review, 25(6), 674-699.

GENÇTÜRK, E. F.; KOTABE, M. The Effect of Export Assistance Program Usage on Export Performance: A Contingency Explanation. Journal of International Marketing, v. 9, n. 2, 2001.

GUBA, E. G., \& Lincoln, Y. S. (2005). Paradigmatic Controversies, Contradictions, and Emerging Confluences. In N. K. Denzin \& Y. S. Lincoln (Eds.), The Sage handbook of qualitative research (pp. 191-215). Thousand Oaks, CA, : Sage Publications Ltd.

GUIMARÃES, Sônia M. K.; AZAMBUJA, L. R. Internacionalização de Micro, Pequenas e Médias Empresas inovadoras no Brasil: Desafios do novo paradigma de Desenvolvimento. REVISTA BRASILEIRA DE CIÊNCIAS SOCIAIS (ONLINE), v. 33, p. 1-19, 2018.

KONIG, C. C. Avaliação do papel das agências de promoção de exportação e investimento nos fluxos de negócios entre países. São Paulo: USP, 2016. 209 f. Tese (Doutorado) - Programa de Pós-Graduação 
em Administração, Universidade de São Paulo, São Paulo, 2016.

LAWRENCE, T. B ve Shadnam, M. (2008) Institutional Theory, in W. Donsbach (der.), The International Encyclopedia of Communication, Oxford, UK, and Malden, Blackwell Publishing, MA, 2288- 2293.

MARANO, V., ARREGLE, J. L., HITT, M. A., SPADAFORA, E; VAN ESSEN, M. 2016. Home country institutions and the internationalizationperformance relationship: A meta-analytic review. Journal of Management, 42(5): 1075-1110.

MDIC- Ministério do Desenvolvimento, Indústria e Comércio Exterior. Comex Stat. Exportação e Importação em geral. Disponível em: < http://comexstat.mdic.gov.br/pt/geral >. Acesso em: Maio/2019.

MEYER, J. W.; ROWAN, B. Institutionalized organizations: formal structure as myth and ceremony. American Journal of Sociology, v. 83, p. 340-363, 1977.

MONTICELLI, J. M.; F; CALIXTO, C. V; DE VASCONCELLOS, S. L; GARRIDO, I. L. A influência de instituições formais na internacionalização das empresas em um país emergente. RBGN-Revista Brasileira de Gestão de Negócios, São Paulo, v. 19, n. 65, p. 358-374, 2017.

MORAES, S. G; STREHLAU, V. I; TUROLLA, F.A. Produção acadêmica de autores brasileiros sobre Internacionalização: Balanço das Publicações no Brasil no Séc. XXI. Revista Eletrônica de Negócios Internacionais da ESPM. São Paulo, v.10, n. 2, p. 8296, 2015.

NGO, V. D; JANSSEN, F; LEONIDOU, L. C; CHRISTODOULIDES, P. Domestic Institutional attributes as drivers of export performance in an emerging and transition economy. Journal of Business Research, 69(8), 2911-2922, 2016.

NORTH, D. Institutions, Institutional Change, and Economic Performance. Cambridge, MA: Harvard University Press, 1990.

PAIVA Jr., F. G., Leão, A. L. M. S., \& Mello, S. C. B. (2007). Validade e confiabilidade na pesquisa qualitativa em Administração. Anais do Encontro de Ensino e Pesquisa em Administração e Contabilidade, Recife, PE, Brasil.

PENG, M. W.; WANG, D.; JIANG, Y. An institutionbased view of international business strategy: A focus on emerging economies. Journal of International Business Studies, v.39, n.5, p.920-936, 2008.

PENG, M. W. Towards an institution-based view of business strategy. Asia Pacific Journal of Management, 19(2/3), 251-267, 2002.

PENG M. W; SUN, S. L; PINKHAM B. , CHEN, $\mathrm{H}$. The institution-based view as a third leg for a strategy tripod. Academy of Management Perspectives, 23(4): 63-81, 2009.

PIEKKARI, R., WELCH, C., PAAVILAINEN, E. (2009). The case study as disciplinary convention: evidence from international business journals. Organizational Research Methods, 12(3), 567-589.

PRAHALAD CK, Mashelkar RA. 2010. Innovation'sholygrail. Harvard Business Review 88 (7/8): 132-141.

PROZCZINSKI, D; STEINBRUCH, A. M. Os obstáculos à internacionalização de empresas inovadoras e o papel dos ambientes de inovação no Brasil. Belém, XXIV Seminário Nacional de Parques Tecnológicos e Incubadoras de Empresas, 2014.

RECKLIES, Dagmar. SMEs - Size as a chance or a Handicap? The manager.org, Mar., 2001 a. Disponivel na internet: http://www.themanager.org/Resources/Small20Busi ness.htm.

SCOTT, W. R. Institutional theory: Contributing to a theoretical research program, 2005.

SEBRAE. Internacionalização das micro e pequenas empresas. Sebrae nacional, 2015. Disponível em: < https://www.sebrae.com.br/sites/PortalSebrae/bis/i nternacionalizacao-das-micro-e-pequenasempresas,8f5836627a963410VgnVCM1000003b740 10aRCRD >. Acessado em: Abril/2019. 
SEBRAE. Estudo econômico do arranjo produtivo local de confecções do Agreste Pernambucano, 2012. Relatório final. Serviço de apoio às Micro e Pequenas Empresas do Estado de Pernambuco Sebrae/Pernambuco. Recife - PE, 2013.

SILVA, M. A. Comércio exterior e inovação industrial: o caso do Agreste de Pernambuco. In: I Encontro em Economia e Desenvolvimento do Agreste de Pernambuco, 2011, Caruaru. Anais do I ENEDAP. Recife: UFPE - CAA, 2011. v. 1.

SILVA, C. R.; GOBBI, B. C.; SIMÃO, A. A. O uso da análise de conteúdo como uma ferramenta para a pesquisa qualitativa: descrição e aplicação do método. Organizações Rurais \& Agroindustriais, v. 7, n. 1, p. 70-81, 2005.

SPERS, R. G; WRIGHT, J. T. C. PMEs Estrangeiras no Brasil: Um estudo sobre os motivos para internacionalizar, formas de entrada e os desafios. In: XI SEMEAD Seminários em Administração, 2008,
São Paulo. Anais do XI SEMEAD. Seminários em Administração, 2008.

TRIVIÑOS, A. Introdução à pesquisa em ciências sociais: a pesquisa qualitativa em educação. São Paulo: Atlas, 1987.

WRIGHT, M; FILATOTCHEV, I; HOSKISSON, R; PENG, M. Strategy research in emerging economies: challenging the conventional wisdom. Journal of Management Studies, 42(1), 1-33, 2005. doi: 10.1111/j.1467-6486.2005.00487.x

XU, D; MEYER, K. Linking theory and context: 'Strategy research in emerging economies' after Wright et al. (2005). Journal of Management Studies, in press, 2013.

YIN, R. K. Estudo de caso: planejamento e métodos. 4. Ed. Porto Alegre: Bookman, 2010

\section{Sobre os autores:}

Ane Izabelle Bezerra de Arruda - Universidade Federal de Pernambuco - UFPE, (Brasil). Email: anearruda12@gmail.com. Orcid id: https://orcid.org/0000-0001-8665-7414

Viviane Santos Salazar - Universidade Federal de Pernambuco - UFPE, (Brasil). Email: viviane_salazar@yahoo.com.br. Orcid id: https://orcid.org/0000-0001-7046-3703 


\section{THE INFLUENCE OF THE FORMAL INSTITUTION IN THE INTERNATIONALIZATION PROCESS OF THE MSMES IN AN EMERGING ECONOMY}

Ane Izabelle Bezerra de Arruda e Viviane Santos Salazar

Universidade Federal de Pernambuco - UFPE, Recife, (Brasil)

\section{ARTICLE DETAILS}

\section{Article history:}

Received: 16 January 2020

Accepted: 27 August 2020

Available online January: 01 th 2021

\section{Double Blind Review System}

Scientific Editor

Ilan Avrichir

\section{Keywords}

Formal institution Institution-based view Export promotion program Internationalization

\section{ABSTRACT}

Objective: The objective of this article is to analyze how an export promotion program, as a formal institution, influences the internationalization process of MSMEs in an emerging economy, under the theoretical perspective of the institution-based view.

Method: Multiple case studies were carried out, comprising a corpus of 9 interviews conducted in a semi-structured manner, with representatives of the formal institution under analysis and MSMEs from the textile and clothing sector of Agreste Pernambucano.

Main Results: A significant influence of the formal institution for the internationalization of MSMEs in the T\&C Sector was identified, especially in the demystification of export myths, information on procedures for internationalization, promotion and support at fairs, adjustments in processes, products and management. However, there are also negative influences such as incipient attention to foreign trade issues, disclosure of the program with political interests, few practical export results, state bureaucracy and exchange rate volatility.

Relevance: The focus on the role of the institutions of the country of origin, especially in emerging economies, in the internationalization of companies, is an emerging theme, therefore, this article can collaborate for the permanence of the local and global relevance of the theme

Theoretical / Methodological Contributions: Uses the theoretical perspective of the institution-based view to understand the interactions between institution and internationalization, contemplating a distinct institutional environment, bringing new perspectives for analysis. 


\section{LA INFLUENCIA DE LA INSTITUCIÓN FORMAL EN EL PROCESO DE INTERNACIONALIZACIÓN DE MPMES EN UNA ECONOMÍA EMERGENTE}

Ane Izabelle Bezerra de Arruda e Viviane Santos Salazar

Universidade Federal de Pernambuco - UFPE, Recife, (Brasil)

\section{HISTORIA DEL ARTÍCULO}

Historia del Artículo:

Recibido: 16 de Enero de 2020

Aceptado: 27 de Agosto de 2020

Disponible en línea: 01 de Enero 2021

Double Blind Review System

Editor Científico

Ilan Avrichir

\section{Palabras-clave:}

Institución formal;

Visión institucional;

Programa de promoción de exportaciones; Internacionalización

\begin{abstract}
RESUMEN
Objetivo: El objetivo de este artículo es analizar cómo un programa de promoción de exportaciones, como institución formal, influye en el proceso de internacionalización de las MIPYMES en una economía emergente, bajo la perspectiva teórica de la mirada institucional.
\end{abstract}

Método: Se realizaron múltiples estudios de caso, que comprenden un corpus de 9 entrevistas realizadas de manera semiestructurada, con representantes de la institución formal bajo análisis y MIPYMES del sector textil y confección de Agreste Pernambucano.

Principales Resultados: Se identificó una influencia significativa de la institución formal para la internacionalización de las MIPYMES en el Sector T\&C, especialmente en la desmitificación de mitos exportadores, información sobre procedimientos de internacionalización, promoción y acompañamiento en ferias, adecuaciones en procesos, productos $y$ gestión. Sin embargo, también existen influencias negativas como la incipiente atención a los temas de comercio exterior, divulgación del programa con intereses políticos, pocos resultados prácticos de exportación, burocracia estatal y volatilidad del tipo de cambio.

Relevancia: El enfoque en el rol de las instituciones del país de origen, especialmente en las economías emergentes, en la internacionalización de las empresas, es un tema emergente, por lo que este artículo puede colaborar para la permanencia de la relevancia local y global del tema.

Contribuciones Teóricas / Metodológicas: Utiliza la perspectiva teórica de la visión institucional para comprender las interacciones entre institución e internacionalización, contemplando un entorno institucional distinto, aportando nuevas perspectivas de análisis.

\section{Como citar este artigo:}

de Arruda, A., \& Salazar, V. (2021). A Influência da Instituição Formal no Processo de Internacionalização das MPMEs em uma Economia Emergente. Internext, 16(1), 36-55. doi: http://dx.doi.org/10.18568/internext.v16i1.592 